\title{
A HISTÓRIA DA CIÊNCIA NOS LIVROS DIDÁTICOS DE QUÍMICA DO PNLEM 2007
}

\author{
The History of Science \\ in the PNLEM 2007' Chemistry 'Textbooks
}

Paulo Henrique Oliveira Vidal ${ }^{1}$. Paulo Alves Porto $^{2}$

Resumo: Este trabalho analisa os seis livros didáticos de química indicados pelo Programa Nacional do Livro Didático para o Ensino Médio em 2007 (PNLEM 2007), no que se refere a seus conteúdos de história da ciência. Para isso, partiu-se do instrumento de análise desenvolvido por L. Leite (2002), que foi adaptado para a presente investigação. Os resultados obtidos indicam, como tendência geral, que a história da ciência é apresentada nos livros didáticos de maneira linear e superficial, constando, sobretudo, de nomes e datas. Dessa maneira, concluímos que os conteúdos de história da ciência desses livros não contribuem para que os alunos desenvolvam uma imagem do empreendimento científico condizente com os objetivos educacionais da atualidade.

Palavras-chave: História da ciência. Livro didático. Ensino de química.

\begin{abstract}
This paper aims to analyze the history of science content of six chemistry textbooks selected in 2007 by the Brazilian National High School Textbook Program (PNLEM 2007). An analysis instrument originally developed by L. Leite (2002), and modified for the present investigation, was used. Results indicate that, in general, the history of science is presented in chemistry textbooks in a linear and superficial fashion, consisting mostly of the mere mention of names, facts and dates. One can conclude that the history of science content of the analyzed textbooks do not contribute to help students to develop an image of the scientific endeavor in keeping with current educational goals.
\end{abstract}

Keywords: History of science. Textbooks. Chemical education.

\footnotetext{
${ }^{1}$ Instituto de Química, Universidade de São Paulo (IQ-USP). Avenida Prof. Lineu Prestes, 748, bloco 7 superior, sala 0761, Cidade Universitária. São Paulo, SP, Brasil. 05.508-000. phoidal@iq.usp.br

${ }^{2}$ Grupo de Pesquisa em História da Ciência e Ensino de Química (GHQ), IQ-USP. São Paulo, SP, Brasil.
} 
Vidal, P. H. O.; Porto, P. A.

\section{Introdução}

Existe uma variedade de livros didáticos no mercado disponíveis aos professores de química - e sua influência sobre o ensino não deve ser desprezada. Pesquisas revelam que os livros didáticos são utilizados, por um lado, pelos professores do Ensino Médio, que os consideram uma importante fonte de informação. Por outro lado, os livros didáticos podem ser utilizados pelos alunos para realizarem atividades extraclasse. Entretanto, para expressivo contingente de alunos brasileiros, provenientes de famílias com baixo poder aquisitivo, talvez o livro didático "represente o único texto com que muitos brasileiros interagem durante suas vidas" (FRACALANZA; AMARAL; GOUVEIA, 1987, p. 28). Machado (1997) argumenta que, devido ao grande público que interage com os manuais didáticos, este seja um tema candente, envolvendo questões muito complexas e que necessitam ser investigadas. Em recente artigo de revisão sobre os desafios enfrentados por aqueles que desejam inserir a história e a filosofia da ciência no ensino escolar de ciências, Höttecke e Silva (2011) apontam diversos aspectos relacionados aos livros didáticos entre os obstáculos a serem considerados. Visando contribuir para esse debate, o objetivo do presente trabalho é investigar o conteúdo de história da ciência presente nos livros didáticos de química aprovados pelo Plano Nacional do Livro Didático para o Ensino Médio (BRASIL, 2007), utilizando, como instrumento crítico, a nova historiografia da ciência. Previamente à apresentação da análise dos livros didáticos, a título de situar este trabalho no panorama atual do ensino de ciências, faremos breves referências a três aspectos que consideramos relevantes: a renovação do ensino de ciências; a evolução da história da ciência e sua importância para o ensino; e a utilização dos livros didáticos.

\section{A renovação do ensino de ciências}

$\mathrm{Na}$ atualidade, parece haver consenso a respeito do papel que a educação desempenha no desenvolvimento dos povos (GIL-PÉREZ; CARVALHO, 2003). Entretanto, é necessário entender de que maneira a educação, incluindo o ensino de ciências, pode auxiliar nesse desenvolvimento. $\mathrm{O}$ ensino de ciências tradicional, baseado na transmissão de conteúdos a serem memorizados pelos alunos e alunas, pouco tem de útil. Freire (1996) nos alerta, no contexto de uma formação docente com perspectiva progressista, que ensinar não é transferir conhecimento, mas criar as possibilidades para a sua própria produção ou construção.

Ao longo das últimas décadas, a finalidade do ensino de ciências sofreu modificações. Segundo Fourez (2004), não há mais espaço para um ensino de ciências que privilegie apenas a memorização de conceitos científicos: é preciso outros níveis de conhecimentos. Para Diaz (2002), o cidadão deve ter a capacidade de compreender, interpretar e atuar sobre a sociedade, participando de forma ativa na resolução de problemas, o que requer a aquisição de conhecimentos científicos. Reid e Hodson (1993) propõem alguns requisitos básicos: conhecimentos de ciência (fatos, conceitos e teorias), saberes e técnicas da ciência (familiarização com os procedimentos da ciência e a utilização de aparelhos e instrumentos), aplicação do conhecimento científico (situações reais e simuladas), resolução de problemas (investigações reais), interação com a tecnologia, questões ético-morais da ciência (estudo da natureza da ciência) e, também, a história e o desenvolvimento da ciência - aspecto que constitui o foco deste trabalho. Santos e Maldaner (2010, p. 14) consideram que: 
A história da Ciência nos livros didáticos ...

ensinar Química no Ensino Médio significa instrumentalizar os cidadãos brasileiros com conhecimentos químicos para que tenham uma inserção participativa no processo de construção de uma sociedade científica e tecnológica comprometida com a justiça e a igualdade social. Isso exige uma seleção rigorosa de conteúdos, desenvolvimento de processos de mediação que propiciem o desenvolvimento cognitivo para aprendizagem de ferramentas culturais para a participação efetiva na sociedade e, sobretudo, o desenvolvimento de valores comprometidos com a sociedade brasileira.

Compartilhando dessa perspectiva, entendemos que a história da ciência pode contribuir para esse processo - ou pode, ao contrário, contribuir para gerar visões distorcidas da ciência, dependendo da forma como for abordada. Se, por um lado, se pode argumentar que é perfeitamente possível aprender conteúdos de ciências sem recorrer à abordagem histórica, também se pode argumentar, por outro lado, que a aprendizagem de conteúdos não deve ser a única preocupação dos atuais educadores em ciências. Além dos conteúdos, que podem ser considerados como os produtos da ciência, também se considera importante aprender aspectos do processo de construção do conhecimento científico - inclusive, sua interação com o contexto social. Para entender como algumas interpretações da história da ciência podem não ser úteis para atingir os objetivos educacionais da atualidade, vamos enfocar, na sequência, de maneira bastante sucinta, algumas questões de caráter historiográfico ${ }^{3}$.

\section{As transformações da história da ciência e sua importância para o ensino}

No início do século XX, surgiram os primeiros esforços no sentido de institucionalizar a história da ciência. As pessoas então consideradas ideais para se especializarem nessa área seriam as provenientes das áreas de ciências da natureza. A história da ciência que se fazia nessa época pressupunha "o desenvolvimento contínuo e acumulativo da ciência. Um processo considerado único, progressivo e inevitável, pois teria seguido a trilha lógica das verdades sobre a natureza" (ALFONSO-GOLDFARB; FERRAZ; BELTRAN, 2004, p. 50). Eram pouco considerados fatores como cultura, política, sociedade, enfim, todo o contexto da época em que fora produzido o conhecimento científico que estivesse em questão. Este tipo de historiografia da ciência - preocupada apenas com os eventos internos à ciência, como a evolução de teorias e conceitos, considerados independentemente da sociedade em que foram desenvolvidos - permaneceu hegemônico nas primeiras décadas do século passado. Na década de 1930, porém, em um congresso de história da ciência realizado em Londres, a comitiva soviética apresentou trabalhos que problematizavam a influência de aspectos sociais no âmbito da construção do conhecimento científico - inaugurando, assim, um intenso debate a respeito da complexa interação da ciência com fatores externos (ALFONSO-GOLDFARB; FERRAZ;

\footnotetext{
${ }^{3}$ Convidamos o leitor interessado em se aprofundar nessas questões a consultar as referências citadas, especialmente a coleção de textos produzidos por diversos especialistas em história da ciência, e organizada por Alfonso-Goldfarb e Beltran (2004).
} 
BELTRAN, 2004, p. 51-52; DEBUS, 1991). A abordagem externalista fez com que aspectos como religião, cultura, política e ambiente social fossem, com o passar do tempo, definitivamente incorporados à historiografia da ciência - de tal forma que o conflito entre "internalismo" e "externalismo" se encontra, hoje, inteiramente superado entre os historiadores da ciência, com o reconhecimento de que ambos os aspectos são necessários para a compreensão da complexidade da transformação do pensamento científico ao longo da história. Entretanto, a abordagem sociológica da ciência produziu também, nas últimas décadas, uma interpretação de acordo com a qual tudo, na ciência, se constitui de construções sociais, desprezando as influências da Natureza nessas construções. Não concordamos com esta abordagem, nem do ponto de vista da produção de conhecimento em história da ciência, nem da conveniência em utilizá-la no ensino de ciências. Preferimos nos alinhar a autores como Pickstone (1995) e Martins (2004), que consideram que o uso de conhecimentos científicos atuais pode enriquecer a interpretação de ideias e relatos do passado, sem perder de vista a ciência como fenômeno cultural e sem incorrer em anacronismos.

Outro debate que contribuiu para transformar profundamente o modo como se entende a história da ciência foi aquele em torno do desenvolvimento contínuo da ciência. Gaston Bachelard (1884-1962), filósofo da ciência francês, foi um dos primeiros a propor, com base em alguns exemplos históricos, que a ciência não evoluiria de maneira linear e contínua, mas por meios de "saltos" - ou seja, ao longo da história teria havido, em algumas ocasiões, o rompimento com uma forma de pensar anterior e sua substituição por outra. Essa ideia não agradou a muitos filósofos contemporâneos de Bachelard, mas abriu caminho para estudos relativos à descontinuidade na ciência, sobretudo nas décadas de 1940 e 1950 . Marco importante nesse debate foi a polêmica obra de Thomas S. Kuhn (1998), A estrutura das revoluções cientificas (no original: The structure of scientific revolutions, publicado em 1962).

O modelo proposto por Kuhn (1998) não está livre de problemas: tendo sido construído a partir de uma determinada perspectiva da história das ciências físicas, o modelo não dá conta da especificidade do desenvolvimento de outras áreas da ciência. Outra dificuldade reside na constatação da existência de tênues linhas de continuidade na prática da ciência, mesmo em momentos de mudanças revolucionárias (ALFONSO-GOLDFARB; FERRAZ; BELTRAN, 2004, p. 52-60; CANGUILHEM, 1977, p. 19-23). Entretanto, a contribuição de Kuhn (1998) foi bastante influente, e os historiadores da ciência passaram a se interessar, cada vez mais, pela especificidade de cada momento histórico, buscando compreender os significados das ideias científicas no contexto histórico em que foram formuladas, e identificando as sutilezas da trama de continuidades e rupturas. Assim, os historiadores da ciência, na atualidade, consideram inadequado interpretar o passado buscando apenas identificar uma sequência linear que teria produzido as ideias do presente (abordagem que já foi chamada de "história whig" ou "presentismo"). Sumarizando, defendemos aqui concepções historiográficas da ciência que levam em consideração a influência parcial da Natureza no processo social de construção da ciência, o estudo minucioso de episódios, obras e autores em seus respectivos contextos (incluindo a caracterização das peculiares interpretações dadas às fontes por diferentes pensadores do passado), na forma de estudos de casos, valorizando a investigação cuidadosa de continuidades e rupturas no processo histórico de construção da ciência. Acreditamos que reflexões sobre questões historiográficas como estas possam contribuir para a formação de educadores em ciência, no sentido de auxiliá-los a desenvolverem abordagens para a história 
A história da Ciência nos livros didáticos ...

da ciência no ensino que estejam de acordo com os objetivos educacionais da atualidade (PORTO, 2010).

Seria um equívoco considerar que as abordagens fundamentadas na história da ciência poderiam solucionar todos os problemas do ensino de ciências (BALDINATO; PORTO, 2007). Entretanto, por meio da história da ciência, é possível propiciar, aos estudantes, maior compreensão acerca das disciplinas científicas - conforme argumentou o destacado historiador da química, Allen G. Debus:

Acredito que seja importante - talvez essencial - para um estudante compreender o papel da ciência em nosso mundo - e acredito que a melhor maneira de se fazer isso é através da história. Este é um recurso precioso para os estudantes entenderem os fatores que afetam a mudança de visão do homem a respeito da natureza [...]. (DEBUS, 1971, p. 804)

Diversos pesquisadores, como Guridi e Arriassecq (2004), Paixão e Cachapuz (2003), Solbes e Traver (2001), Khalick e Lederman (2000), Matthews (1994), entre outros, têm defendido o potencial didático da história da ciência. Entre os benefícios desse tipo de abordagem para o ensino de ciências, Matthews (1994) aponta que a história da ciência pode: humanizar as ciências e relacioná-las aos interesses éticos, culturais e políticos; deixar as aulas mais estimulantes e reflexivas, desenvolvendo o pensamento crítico dos alunos; contribuir para uma compreensão maior dos conteúdos científicos; e melhorar a formação dos professores, contribuindo para o desenvolvimento de uma epistemologia da ciência mais rica e mais autêntica em sala de aula. Diversas pesquisas revelam que a exclusiva e monótona memorização de conteúdos pode gerar uma visão deformada da ciência. Segundo Cachapuz et al. (2005), o ensino descontextualizado, baseado na transmissão, produz uma concepção de ciência socialmente neutra, que deixa obscuras dimensões essenciais da atividade científica e tecnológica.

Martins (2006) defende que, através de estudos de casos minuciosos em história da ciência, pode-se desenvolver a compreensão da complexa relação entre ciência, tecnologia e sociedade, demonstrando que a ciência não é uma atividade isolada de todas as outras, mas parte de um contexto no qual influencia e é influenciada. Dessa forma, o aluno teria a oportunidade de observar que a ciência resulta de um processo social (coletivo) e gradativo de construção do conhecimento, que possui suas limitações e procedimentos intrincados - ou seja, que a ciência não aparece, repentinamente, na mente de "gênios" isolados que geram o conhecimento. Assim, o estudo histórico de como um cientista realmente desenvolveu sua pesquisa ensina mais sobre o real processo científico do que qualquer manual de metodologia científica. Martins (2006) também defende a ideia de que o estudo detalhado de alguns episódios da história da ciência é insubstituível na formação de uma concepção adequada sobre a natureza das ciências, incluindo suas limitações e suas relações com outros campos da cultura.

Para fazer com que a história da ciência efetivamente contribua para esse processo de aprendizagem da ciência, o professor precisará dispor de fontes para consulta que sejam coerentes com seus propósitos, a fim de auxiliá-lo no processo de ensino. Considerando-se a larga utilização dos livros didáticos como fontes de consulta por boa parte dos professores do Ensino Médio, conforme apontam, por exemplo, Mortimer (1988) e Lopes (1992), é razoável 
Vidal, P. H. O.; Porto, P. A.

supor que esses educadores também irão recorrer aos livros didáticos em busca de informações sobre a história da ciência.

\section{A importância de investigar o livro didático}

Segundo Fracalanza, Amaral e Gouveia (1987), a escolha do livro didático como objeto de investigação decorre de dois fatores principais. O primeiro leva em consideração o aumento do número de vagas nas escolas de Ensino Fundamental e Médio a partir dos anos 1960, e o segundo fator está relacionado ao aumento do número de professores egressos de instituições privadas de ensino. Muitos desses docentes, devido à falta de atualização adequada para a prática docente, ou às lacunas existentes em seus cursos de licenciatura, passaram a depender cada vez mais dos manuais escolares. Em face de sua larga presença na prática pedagógica, os livros didáticos passaram a ser objeto de análises caracterizadas por diversos estilos e objetivos. Os aspectos analisados incluem: a produção, a comercialização, a inserção do conhecimento na evolução histórica, a qualidade gráfica e a adequação de conteúdos dos livros didáticos. As relações entre os livros didáticos e as produções curriculares nas escolas também são temáticas constantes em artigos, dissertações e livros. Dentre os aspectos citados por Loguércio (2001), a respeito dessas investigações, destaca-se a importância da elaboração de novos critérios para análise dos livros didáticos, com a intenção de aprimorar, cada vez mais, a escolha consciente em relação aos conteúdos e a sua finalidade, e quais as limitações de um livro didático. Entretanto, muito ainda há para ser feito, especialmente em relação aos livros didáticos de química do Ensino Médio.

Fracalanza (2005), em seu estudo que teve como objetivo investigar as pesquisas sobre o livro didático de ciências no Brasil, observou que a produção acadêmica sobre esse tema, nos últimos trinta anos, foi constituída por setenta e cinco teses. Pode parecer um número substancial; todavia, desse total, quarenta e quatro trabalhos estão voltados a livros para o Ensino Médio, e apenas nove estão relacionados com o livro didático de química. Podemos inferir que, em um país de extensão continental, apenas nove trabalhos envolvendo os livros didáticos dessa área é um número ainda pequeno. Por isso, este trabalho busca oferecer uma contribuição ao debate, investigando como a história da ciência está presente em livros didáticos de química.

\section{Metodologia}

Para esta investigação, escolhemos os seis livros que foram selecionados pelo Plano Nacional do Livro Didático do Ensino Médio - PNLEM (BRASIL, 2007). Embora reconhecendo que a amostra é pequena, em face do número de livros didáticos de química editados no Brasil, consideramos a amostra significativa, em função de sua extensiva distribuição em todo o território nacional. Nesse sentido, seu potencial impacto sobre o ensino de química no Brasil é bastante considerável.

Os livros escolhidos estão no Quadro 1. 
A história da Ciência nos livros didáticos ...

Quadro 1. Livros escolhidos

\begin{tabular}{|c|l|}
\hline $\begin{array}{c}\text { Código de } \\
\text { identificação }\end{array}$ & \multicolumn{1}{c|}{ Referências } \\
\hline LD1 & $\begin{array}{l}\text { BIANCHI, J. C. A.; ALBRECHT, C. H.; MAIA, D. J. Universo da química: ensino médio. } \\
\text { São Paulo: FTD, 2005. }\end{array}$ \\
\hline LD2 & FELTRE, R. Química geral. 5. ed. São Paulo: Moderna, 2000. v. 1. \\
\hline LD3 & $\begin{array}{l}\text { PERUZZO, F. M.; CANTO, E. L. Química geral e inorgânica. 3. ed. São Paulo: Moderna, } \\
\text { 2003. v. 1. }\end{array}$ \\
\hline LD4 & MORTIMER, E. F.; MACHADO, A. H. Química. São Paulo: Scipione, 2005. \\
\hline LD5 & NÓBREGA, O. S.; SILVA, E. R.; SILVA, R. H. Química. São Paulo: Ática, 2005. \\
\hline LD6 & SANTOS, W. L. P.; MOL, G. S. Química e sociedade. São Paulo: Nova Geração, 2005. \\
\hline
\end{tabular}

Fonte: Vidal (2009)

As categorias utilizadas para a análise dos conteúdos relacionados à história da ciência foram inspiradas no trabalho de Laurinda Leite (2002), o qual nosso grupo também utilizou, em outra investigação, para análise de livros do Ensino Superior (FERNANDES; PORTO, 2012). O instrumento original sofreu algumas modificações para melhor se adequar a nosso processo investigativo. Para cada livro, procedemos, inicialmente, à marcação de todas as ocorrências relacionadas à história da ciência: textos presentes no corpo dos capítulos, ilustrações, exercícios, caixas de textos e seções sugerindo leituras complementares. Todas essas ocorrências foram, então, classificadas de acordo com as categorias que constam do instrumento proposto por Leite (2002), e modificado por nós, conforme será explicado a seguir. As atribuições foram feitas de maneira independente por dois pesquisadores, e os casos discrepantes foram discutidos até se chegar a um consenso. Do total de oito dimensões analisadas em nossa investigação quantitativa e qualitativa, selecionamos quatro para discussão no presente artigo.

\section{Resultados}

Os resultados obtidos estão a seguir. As tabelas 1 a 4 trazem sempre dois números para cada categoria observada em cada livro: o primeiro é o número absoluto de ocorrências para aquela categoria; o segundo número refere-se à porcentagem correspondente, considerando-se o número total de ocorrências para aquela dimensão.

\section{Dimensão 1) Vida dos personagens (filósofos, pensadores ou cientistas)}

1.1) Biografia (pelo menos nome, e as datas de nascimento e morte).

1.2) Características pessoais (sentimentos, caráter, humor etc.).

1.3) Episódios / curiosidades (casado com..., decapitado por...).

Leite (2002) utiliza, em seu instrumento, apenas a denominação "cientista". Para maior precisão, preferimos adicionar, também, ao título da categoria, as denominações "filósofos" e "pensadores", considerando que o termo cientista somente começou a ser utilizado na sua acepção atual no decorrer do século XIX (KRAGH, 1987, p. 25). 
Vidal, P. H. O.; Porto, P. A.

Tabela 1. Vida dos personagens

\begin{tabular}{lrrrrrrrrrrrr}
\hline Vida dos personagens & \multicolumn{2}{c}{ LD1 } & \multicolumn{2}{c}{ LD2 } & \multicolumn{2}{c}{ LD3 } & \multicolumn{2}{c}{ LD4 } & \multicolumn{2}{c}{ LD5 } & \multicolumn{2}{c}{ LD6 } \\
\hline Dados biográficos & 217 & 98 & 80 & 85 & 77 & 95 & 104 & 99 & 89 & 99 & 296 & 96 \\
Características pessoais & - & - & - & - & - & - & - & - & 1 & 1 & 1 & 0,1 \\
Episódios / curiosidades & 4 & 2 & 14 & 15 & 4 & 5 & 1 & 1 & - & - & 12 & 3,9 \\
Totais & 221 & 100 & 94 & 100 & 81 & 100 & 105 & 100 & 90 & 100 & 309 & 100 \\
\hline
\end{tabular}

Fonte: Vidal (2009).

Grande parte dos dados relativos à vida dos personagens se restringe apenas ao nome e às datas de nascimento e morte - em todos os livros esse aspecto corresponde a mais de $85 \%$ das ocorrências para essa dimensão. Dificilmente, encontramos descrições de aspectos da vida pessoal dos cientistas, pesquisadores ou filósofos. Esse tipo de abordagem, ao não dar uma dimensão humana aos personagens da ciência, não favorece a superação de estereótipos bastante difundidos - como o de que os cientistas são pessoas que trabalham isoladas, por possuírem uma inteligência exclusiva de uma ínfima parcela da população (CACHAPUZ et al., 2005).

\section{Dimensão 2) Abordagem das ideias / descobertas}

2.1) Menção a uma ideia científica (uma descoberta, ou, de modo mais geral, uma ideia científica é mencionada).

2.2) Descrição de uma ideia científica (a ocorrência de uma descoberta ou ideia é descrita).

Consideramos menção a uma ideia científica quando esta é apenas citada, sem maiores explicações (por exemplo, "cientista X descobriu o fenômeno Y", ou "cientista X formulou a lei Y"). Quando, porém, o texto inclui explicações a respeito da metodologia, teoria, circunstâncias - enfim, algum detalhamento a respeito do modo como a ideia foi originada - , classificou-se como descrição da ideia científica.

Tabela 2. Abordagem das ideias/ descobertas

\begin{tabular}{|c|c|c|c|c|c|c|c|c|c|c|c|}
\hline \multirow{2}{*}{$\begin{array}{l}\text { Abordagem das ideias / descobertas } \\
\text { Menção a uma ideia científica }\end{array}$} & \multicolumn{2}{|c|}{ LD1 } & \multicolumn{2}{|c|}{ LD2 } & \multicolumn{2}{|c|}{ LD3 } & \multirow{2}{*}{$\begin{array}{c}\text { LD4 } \\
6387,5\end{array}$} & \multicolumn{2}{|c|}{ LD5 } & \multicolumn{2}{|c|}{ LD6 } \\
\hline & 169 & 94 & 59 & 96 & 41 & 85 & & 72 & 90 & 212 & 99 \\
\hline Descricãa de uma ideia científica & 10 & 6 & 2 & 4 & 7 & 15 & 912,5 & 8 & 10 & 2 & 1 \\
\hline Totais & 179 & 100 & 61 & 100 & 48 & 100 & $72 \quad 100$ & 80 & 100 & 214 & 100 \\
\hline
\end{tabular}

Fonte: Vidal (2009).

Os resultados obtidos mostram o predomínio da simples menção às ideias científicas, em relação a descrições das ideias em sua construção histórica. $O$ trecho a seguir é exemplo de menção a ideias científicas, que não se fazem acompanhar de maiores explicações a respeito de como foram geradas, quais os questionamentos que conduziram a elas etc.: 
A história da Ciência nos livros didáticos ...

Proust concluiu que a composição química das substâncias compostas é sempre constante, não importando sua origem. Em outras palavras, uma certa substância composta, seja obtida de fontes naturais ou produzida em laboratório, sempre é formada pelos mesmos elementos químicos numa mesma proporção, em massa. Essa generalização ficou conhecida como Lei das Proporções Constantes, ou Lei de Proust. (PERUZZO; CANTO, 2003, p. 48)

O fragmento transcrito a seguir, por sua vez, fornece exemplo do que consideramos como descrição de ideias científicas:

Esse [i.e., o gás carbônico] foi o primeiro gás a ser isolado e a ter suas propriedades determinadas, o que foi feito pelo escocês Joseph Black (1728-1799). Black fez reagir ácido com magnésia (carbonato de magnésio) $\left[\mathrm{MgCO}_{3}\right]$, obtendo um sal e um gás, o que foi chamado "ar fixo", uma vez que, de alguma forma, estaria "preso" à substância sólida utilizada. Esse gás também foi obtido pelo aquecimento da magnésia. Estudando as propriedades do "ar fixo", Black observou que se tratava de um gás diferente do "ar" já conhecido, pois não mantinha a chama de uma vela. Além disso, quando se colocava água de cal (solução de hidróxido de cálcio) em um frasco com esse gás, ocorria a formação de um sólido branco. Desse modo, Black também demonstrou que o "ar fixo" possuía grande semelhança com o ar expirado pelos seres vivos. (NÓBREGA; SILVA; SILVA, 2005, p. 239)

A simples menção a uma ideia ou descoberta científica está presente nos livros sempre com incidências superiores a 80\%. Esses números apontam para o fato de que a informação histórica apresentada nos livros didáticos é, predominantemente, ligeira e superficial. A simples menção não favorece reflexões a respeito do processo de construção do conhecimento científico, e, em geral, serve apenas para apresentar, exemplificar ou reforçar conteúdos.

\section{Dimensão 3) Evolução da ciência}

3.1) Menção a períodos discretos (dois ou mais períodos ou ideias são mencionados, mas não são relacionados entre si).

3.2) Evolução linear e direta (um período é relacionado ao seguinte, mantendo uma direção).

3.3) Evolução real (movimento de "idas e voltas" entre opiniões, incluindo controvérsias).

Consideramos períodos discretos quando o texto não inclui um encadeamento explícito entre duas ou mais ideias científicas ocorridas em períodos distintos. Quando o texto apresenta diversos eventos em sequência, sugerindo que um seguiu naturalmente o anterior, classificamos como evolução linear e direta. Finalmente, os casos em que as ideias científicas são apresentadas de maneira a sugerir descontinuidades, controvérsias, retomadas de ideias antes abandonadas, foram classificados como exemplos de evolução real da ciência. 
Vidal, P. H. O.; Porto, P. A.

Tabela 3. Evolução da ciência

\begin{tabular}{|c|c|c|c|c|c|c|c|c|c|c|c|c|}
\hline \multirow{2}{*}{$\frac{\text { Evolução da ciência }}{\text { Menção a períodos discretos }}$} & \multicolumn{2}{|c|}{ LD1 } & \multicolumn{2}{|c|}{ LD2 } & \multicolumn{2}{|c|}{ LD3 } & \multicolumn{2}{|c|}{ LD4 } & \multicolumn{2}{|c|}{ LD5 } & \multicolumn{2}{|c|}{ LD6 } \\
\hline & 6 & 13 & - & - & 3 & 21 & 6 & 21 & 9 & 33 & 6 & 13 \\
\hline Evolução linear e direta & 32 & 71 & 10 & 100 & 11 & 79 & 20 & 69 & 17 & 63 & 38 & 81 \\
\hline Evolução real & 7 & 16 & - & - & - & - & 3 & 10 & 1 & 4 & 3 & 6 \\
\hline Totais & 45 & 100 & 10 & 100 & 14 & 100 & 29 & 100 & 27 & 100 & 47 & 100 \\
\hline
\end{tabular}

Fonte: Vidal (2009).

Os resultados obtidos mostram um pequeno numero de incidências no que diz respeito aos relatos que descrevem a evolução da ciência através de menção a períodos discretos, como no exemplo que se segue:

O mundo científico habituou-se a ver o físico francês Henri Becquerel e o casal franco-polonês Pierre e Marie Curie como os primeiros desbravadores do mundo das partículas radioativas. Isso é verdade em parte - sem as experiências e observações deles e de outros físicos, apresentadas a partir de 1896 na Academia de Ciências de Paris, não haveria oportunidade para novas descobertas e hipóteses. Mas foi o trabalho teórico de dois físicos, Ernest Rutherford, da Nova Zelândia, e Frederic Soddy, da Inglaterra, que efetivamente explicou como ocorrem as atividades radioativas. Entre novembro de 1902 e maio de 1903, eles publicaram uma serie de cinco artigos em que apresentavam a hipótese de que a radioatividade está associada a fenômenos atômicos de desintegração [...]. (BIANCHI; ALBRECHT; MAIA, 2005, p. 78)

Observa-se que, na maioria das vezes, as transformações da ciência são descritas como um processo linear e direto - como se o conhecimento fosse simplesmente sendo melhorado com o passar do tempo, sem controvérsias ou rupturas. Bizzo (1992, p. 29) critica essa forma de se introduzir a história da ciência no ensino:

A primeira questão a ser colocada é a de que a ideia do passado auxiliando a compreensão do presente pressupõe a existência de um continuum entre um momento e outro. Em outras palavras, a ideia aplicada ao ensino das Ciências demanda um conceito na qual as teorias de hoje sejam vistas como estreitamente aparentadas com as teorias do passado. A compreensão do passado equivaleria à compreensão de parte significativa do presente.

O seguinte trecho é representativo da categoria "evolução linear e direta":

O cientista inglês John Joseph Thomson, elaborando melhor as experiências feitas com tubos catódicos, foi capaz de concluir, em 1887, que os raios catódicos são, na verdade, constituídos pelo fluxo de par- 
A história da Ciência nos livros didáticos ...

tículas menores que o átomo e dotadas de carga elétrica negativa. Estava descoberta a partícula que chamamos de elétron. Após essa descoberta, estava provado que o átomo não é indivisível como imaginavam os filósofos gregos ou como sugeria o modelo de Dalton. (PERUZZO; CANTO, 2003, p. 65, grifos nossos)

Os termos em negrito podem sugerir, implicitamente, algumas concepções inadequadas sobre o processo de construção da ciência. Os estudantes podem assimilar a ideia de que um único experimento, em uma determinada data, seria capaz de "derrubar", uma teoria, levando imediatamente a uma outra. Kuhn (1998, p. 78) argumentou que as descobertas "não são eventos isolados, mas episódios prolongados, dotados de uma estrutura que reaparece regularmente". Ou seja, a transformação das ideias científicas não segue automaticamente o resultado de um experimento, e o uso da palavra "comprovar", nesse contexto, é problemática. Mais importante do que apenas enumerar linearmente a sucessão de "descobertas" ou ideias, seria procurar discutir, com os estudantes, que "a descoberta de um novo tipo de fenômeno é necessariamente um acontecimento complexo que envolve o reconhecimento tanto da existência de algo, como de sua natureza" (KUHN, 1998, p. 81). A simples menção a uma "descoberta" não fornece elementos para que docentes e discentes construam uma concepção plausível de ciência, que lhes dê uma adequada visão a respeito das controvérsias e acontecimentos equívocos que povoam a ciência através dos tempos.

Finalmente, dois exemplos classificados como "evolução real da ciência" são citados a seguir:

A concepção dos alquimistas de um universo vivo e compreendido por meio de signos e símbolos começa a romper-se no século XVII, dando lugar a uma interpretação quantitativa e mecanicista do mundo e da matéria. A interpretação quantitativa foi possível graças ao aprimoramento de instrumentos de medida, como a balança. A interpretação mecanicista baseava-se na ideia de que os fenômenos naturais são regidos por leis que podem ser formuladas matematicamente. Essa concepção de mundo rejeita qualquer interpretação abstrata ou subjetiva dos fenômenos [...]. (NÓBREGA; SILVA; SILVA, 2005, p. 15)

Planck e outros cientistas de sua época tiveram dificuldades em aceitar a teoria quântica, que mudava completamente a maneira de ver os fenômenos em escala atômica. Essa teoria, no entanto, abriria um novo caminho para entender o átomo, com a proposta de Niels Bohr de um modelo para o átomo. (MORTIMER; MACHADO, 2005, p. 104)

Observa-se, nos dois casos, referências a rupturas, a formas concorrentes de se interpretar o mundo físico. Embora trechos assim sucintos não garantam que os alunos irão desenvolver uma ideia a respeito da complexidade da atividade científica, ainda assim são importantes para marcar que a ciência não se faz por acúmulo de informações. 
Vidal, P. H. O.; Porto, P. A.

\section{Dimensão 4) Quem faz a ciência}

4.1) Cientistas, filósofos ou pensadores individuais (um personagem é apresentado como sendo o único responsável por uma ideia ou descoberta).

4.2) Grupo de filósofos, pensadores ou cientistas (dois ou mais personagens trabalharam juntos com o mesmo propósito).

4.3) Comunidade científica (cientistas, filósofos ou pensadores de um período são responsáveis pela ideia ou descoberta, sem que haja especificação de nomes).

A Tabela 4 reúne os dados a respeito de a quem os livros didáticos atribuem as transformações na ciência.

Tabela 4. Quem faz a ciência

\begin{tabular}{lrrrrrrrrrrrr}
\hline \multicolumn{1}{c}{ Quem faz a ciência } & \multicolumn{2}{c}{ LD1 } & \multicolumn{2}{c}{ LD2 } & \multicolumn{2}{c}{ LD3 } & \multicolumn{2}{c}{ LD4 } & \multicolumn{2}{c}{ LD5 } & \multicolumn{2}{c}{ LD6 } \\
\hline Personagens individuais & 140 & 85 & 49 & 90,7 & 29 & 74 & 48 & 87 & 72 & 95 & 185 & 87 \\
Grupos de personagens & 19 & 12 & 3 & 5,5 & 7 & 18 & 7 & 13 & 2 & 2,5 & 24 & 11 \\
Comunidade científica & 6 & 3 & 2 & 3,8 & 3 & 8 & - & - & 2 & 2,5 & 3 & 2 \\
Totais & 165 & 100 & 54 & 100 & 39 & 100 & 55 & 100 & 76 & 100 & 212 & 100 \\
\hline
\end{tabular}

Fonte: Vidal (2009).

Verifica-se uma elevada incidência da concepção de que a ciência é desenvolvida pelo trabalho de personagens individuais. Segue-se um exemplo:

Em 1932, o cientista James Chadwick provou que no núcleo, além de prótons (que são positivos), existem também partículas sem carga elétrica, que por esse motivo foram denominadas nêutrons - confirmando-se assim a existência da terceira partícula subatômica. De certa maneira, os nêutrons "isolam" os prótons, evitando suas repulsões e o consequente "desmoronamento" do núcleo. (FELTRE, 2000, p. 89, grifo nosso)

Por outro lado, a ideia de que a atividade científica resulta da colaboração entre os cientistas, ou por uma comunidade, tem destaque relativamente menor. $\mathrm{O}$ fragmento a seguir exemplifica a referência a grupos de personagens da ciência:

As propostas para a existência dessas partículas [prótons, nêutrons e elétrons] foram sendo elaboradas na tentativa de explicar resultados de experimentos feitos ao longo do século XIX e início do século XX. Em 1911, já se conhecia a existência de elétrons e prótons, mas não se tinha uma ideia precisa sobre como essas partículas se distribuíam no átomo. Como resultado dos experimentos realizados desde 1909 por Geiger e Marsden, sob a sua supervisão, Rutherford foi capaz de elaborar esse novo modelo para o átomo, introduzindo ideias que seri- 
A história da Ciência nos livros didáticos ...

am preservadas em modelos posteriores - a existência do núcleo atômico e da eletrosfera. Os esforços desses pesquisadores resultaram no desenvolvimento de métodos mais modernos de contagens de partículas radioativas, que culminaram no desenvolvimento do contador Geiger, que recebeu esse nome em homenagem ao aluno de Rutherford. (MORTIMER; MACHADO, 2005, p. 95-96, grifos nossos)

Finalmente, para exemplificar um dos escassos relatos da contribuição de comunidades científicas, pode-se citar o trecho a seguir:

As diferenças entre os diversos sistemas de medida criavam obstáculos na comunicação científica. Por essa razão, no século XVII, cientistas europeus mostravam a importância de um sistema de medidas que fosse adotado pelas diversas nações. Por recomendação da Academia Francesa de Ciências, em 1799 adotou-se como unidade de comprimento o metro, cuja definição estabeleceu que equivaleria à décima milionésima parte da distância do pólo Norte ao equador, pelo meridiano que passa por Paris. (BIANCHI; ALBRECHT; MAIA, 2005, p. 137)

A caracterização mais adequada do empreendimento científico deveria incluir seu caráter coletivo, procurando fazer com que os alunos compreendessem que o conjunto de conhecimentos, procedimentos, ferramentas e costumes característicos do fazer científico atual resultam da dinâmica da comunidade de pesquisadores, como sugere Martins (2006, p. xviii):

Nosso conhecimento foi sendo formado lentamente, através da contribuição de muitas pessoas sobre as quais nem ouvimos falar e que tiveram importante papel na difusão e aprimoramento da ideias dos cientistas [ou filósofos, ou pensadores] mais famosos, cujos nomes conhecemos.

Ocorrências classificadas na categoria "comunidade científica" podem contribuir para desenvolver a ideia de que quem faz ciência também está inserido em um grupo, ou comunidade, de pessoas que trabalham com os mesmos objetivos.

\section{Considerações finais}

Não se pode desconsiderar que as informações a respeito da história da ciência, presentes nos livros didáticos analisados neste trabalho, podem influenciar as visões de ciência que serão construídas pelos alunos em seu processo de aprendizagem em ciências - dada a importância do livro didático como referência do saber escolar. Essa importância pode ser ilustrada pela análise feita por Echeverria, Mello e Gauche (2008, p. 75), a respeito da formação de professores de química: 
Vidal, P. H. O.; Porto, P. A.

[...] a profissão docente é culturalmente desvalorizada, o que permite que profissionais de outras áreas, sem qualificação para o ensino, assumam a função pedagógica. O professor leigo não sabe por que ensina os conteúdos que ensina nem por que "é adotado" por esse ou aquele livro didático. Mais ainda, não tem condições de avaliar o livro didático que está usando. Por outro lado, mesmo aqueles professores que são formados em cursos específicos de formação de professores nem sempre fizeram, ao longo da formação inicial, um estudo sobre livros didáticos. Argumentamos que esses são alguns dos motivos que fazem do livro didático "o material didático" dos cursos de química do ensino médio.

Por exemplo: levando em consideração a vida e características dos personagens que fizeram a ciência - analisadas na primeira dimensão do instrumento utilizado neste trabalho observamos que a maior parte dos relatos históricos contidos nos livros didáticos investigados estão relacionados a cientistas individuais. Tal abordagem não colabora para o desenvolvimento da concepção de que a ciência é, essencialmente, um empreendimento coletivo.

Levando em consideração os relatos contidos nos livros didáticos a respeito das origens das ideias científicas, observamos que, na maioria dos casos, a ideia ou a descoberta é apenas citada. Essa maneira simplista de abordar a história da ciência tampouco contribui, de maneira satisfatória, para um entendimento de como a ciência se desenvolve. Outra característica que aponta para uma abordagem simplista é o predomínio da concepção de evolução linear da ciência. Como foi visto, são escassos os casos que descrevem divergências de pontos de vista, ou de metodologias, que estiveram em disputa em episódios da história da ciência. As controvérsias desempenham papel muito importante nos processos de transformação da ciência, mas os autores de livros didáticos fazem escassas referências a elas. Para incorporá-las de maneira efetiva aos materiais didáticos, seria necessário superar a superficialidade na abordagem, recorrendo a estudos de caso mais aprofundados. Estes poderiam ser desenvolvidos pelos próprios autores dos livros didáticos ou, então, poderiam ser buscados em fontes secundárias em história da ciência que estejam atualizadas em termos historiográficos.

Esse tipo de abordagem propiciaria não apenas a construção de ideias mais adequadas a respeito da natureza do conhecimento científico, ou mesmo a construção dos próprios conceitos científicos, mas também poderia auxiliar os estudantes a entenderem melhor como a ciência resulta do contexto social em que ela é produzida, e como influi sobre a sociedade. Não estamos sugerindo aqui que todos os conteúdos de química dos livros didáticos sejam apresentados sob a abordagem histórica, ou que se detalhem as vidas e obras de todos os pensadores do passado citados, o que seria evidentemente inviável. Acreditamos, como Allchin (2004) e Martins (2006), entre outros autores, que a abordagem de um único estudo de caso, de maneira aprofundada, é mais útil para a construção de uma imagem apropriada do empreendimento científico, do que dezenas de simples menções a nomes e datas. Ou seja, se os autores de livros didáticos pretendem incorporar a história da ciência em seus livros, não deveriam se preocupar em inserir grande quantidade de informações pontuais, mas em desenvolver estudos de casos adequados aos objetivos que se pretende alcançar com o ensino de ciências. Nesse sentido, os dados quantitativos fornecidos pelo instrumento desenvolvido por 
A história da Ciência nos livros didáticos ...

Leite (2002), e adaptado no presente estudo, não podem prescindir de uma criteriosa análise qualitativa, como a que procuramos aqui apresentar. Finalmente, considerando os resultados obtidos com os livros que foram objeto desta investigação, se o professor desejar desenvolver, em seus alunos, as habilidades relacionadas à reflexão sobre aspectos históricos e culturais do conhecimento científico, preconizadas nas diretrizes curriculares nacionais para o ensino de química, precisará buscar outros materiais, complementares ao livro didático.

\section{Agradecimentos}

Os autores agradecem ao Conselho Nacional de Desenvolvimento Científico e Tecnológico (CNPq) e à Fundação de Amparo à Pesquisa do Estado de São Paulo (FAPESP) pelo financiamento desta pesquisa. Agradecem, também, aos assessores anônimos de Ciência \& Educação, pelas sugestões para o aperfeiçoamento do artigo.

\section{Referências}

ALFONSO-GOLDFARB, A. M.; BELTRAN, M. H. R. (Org.). Escrevendo a história da ciência: tendências, propostas e discussões historiográficas. São Paulo: EDUC; Livraria Editora da Física; Fapesp, 2004.

ALFONSO-GOLDFARB, A. M.; FERRAZ, M. H. M.; BELTRAN, M. H. R. A historiografia contemporânea e as ciências da matéria: uma longa rota cheia de percalços. In: ALFONSO-GOLDFARB, A. M.; BELTRAN, M. H. R. (Org.). Escrevendo a história da ciência: tendências, propostas e discussões historiográficas. São Paulo: EDUC; Livraria Editora da Física; Fapesp, 2004. p. 49-73.

ALLCHIN, D. Pseudohistory and pseudoscience. Science \& Education, Dordrecht, v. 13, n. 3, p. 179-195, 2004.

BALDINATO, J. O.; PORTO P. A. Variações da história da ciência no ensino de ciências. In: ENCONTRO NACIONAL DE PESQUISA EM EDUCAÇÃO EM CIÊNCIAS, 6., 2008, Florianópolis. Anais... Belo Horizonte: ABRAPEC, 2008. 1 CD-ROM.

BIANCHI, J. C. A.; ALBRECHT, C. H.; MAIA, D. J. Universo da química: ensino médio. São Paulo: FTD, 2005.

BIZZO, N. M. V. História da ciência e ensino: onde terminam os paralelos possíveis? Em Aberto, Brasília, v. 11, n. 55, p. 29-35, jul./set.1992. 
Vidal, P. H. O.; Porto, P. A.

BRASIL. Ministério da Educação. Plano Nacional do Livro Didático para o Ensino Médio - PNLEM. Brasília, 2007. Disponível em: <http://portal.mec.gov.br/

index.php?id=13608\&option=com_content\&view $=$ article $>$. Acesso em: 26 set. 2011.

CACHAPUZ, A. et al. (Org.). A necessária renovação do ensino de ciências. São Paulo: Cortez, 2005.

CANGUILHEM, G. Ideologia e racionalidade nas ciências da vida. Lisboa: Edições 70, 1977.

DEBUS, A. G. A ciência e as humanidades: a função renovadora da indagação histórica. Revista da Sociedade Brasileira de História da Ciência, São Paulo, v. 5, p. 3-13, 1991.

The relationship of science-history to the history of science. Journal of Chemical Education, Easton, v. 48, n. 12, p. 804-805, 1971.

DIAZ, M. J. M. Enseñanza de las ciencias? Para qué? Revista Electrónica Enseñanza de las Ciencias, v. 1, n. 2, p. 1-6, 2002. Disponível em: <www.saum.uvigo.es/reec/ volumenes.htm>. Acesso em: 26 set. 2011.

ECHEVERRIA, A.; MELLO, I. C.; GAUCHE, R. O programa nacional do livro didático de química no contexto da educação brasileira. In: ROSA, M. I. P.; ROSSI, A. V. (Org.).

Educação química no Brasil: memórias, políticas e tendências. Campinas: Átomo, 2008. p. 63-83.

FELTRE, R. Química geral. 5. ed. São Paulo: Moderna, 2000. v. 1.

FERNANDES, M. A. M.; PORTO, P. A. Investigando a presença da história da ciência em livros didáticos de química geral para o ensino superior. Química Nova, São Paulo, v. 35, n. 2, p. 420-429, 2012.

FOUREZ, G. A. Crise no ensino de ciências? Investigações em Ensino de Ciências, Porto Alegre, v. 8, n. 2, p. 1-19, 2004.

FRACALANZA, H. A pesquisa sobre o livro didático de ciências no Brasil. In: ROSA, M. I. P. (Org.). Formar: encontros e trajetórias com professores de ciências. São Paulo: Escrituras, 2005. p. 41-80.

FRACALANZA, H.; AMARAL, I. A.; GOUVEIA, M. S. F. O ensino de ciências no primeiro grau. São Paulo: Atual, 1987.

FREIRE, P. Pedagogia da autonomia: saberes necessários à prática educativa. Rio de Janeiro: Paz e Terra, 1996.

GIL-PÉREZ, D.; CARVALHO, A. M. P. Formação de professores de ciências. São Paulo: Cortez, 2003.

GURIDI, V.; ARRIASSECQ, I. Historia y filosofia de las ciencias en la educación polimodal: propuesta para su incorporación al aula. Ciência \& Educação, Bauru, v. 10, n. 3, p. 307-316, 2004. 
A história da Ciência nos livros didáticos ...

HÖTTECKE, D.; SILVA, C. C. Why implementing history and philosophy in school science education is a challenge: an analysis of obstacles. Science $\boldsymbol{\&}$ Education, Dordrecht, v. 20, n. 3-4, p. 293-316, 2011.

KHALICK, A.; LEDERMAN, N. Improving science teachers' conceptions of nature of science: a critical review of the literature. International Journal of Science Education, London, v. 22, n. 7, p. 665-701, 2000.

$\mathrm{KRAGH}, \mathrm{H}$. An introduction to the historiography of science. Cambridge: Cambridge University Press, 1987.

KUHN, T. A estrutura das revoluções científicas. São Paulo: Perspectiva, 1998.

LEITE, L. History of science in science education: development and validation of a checklist for analysing the historical content of science textbooks. Science $\boldsymbol{\&}$ Education, Dordrecht, v. 11, n. 4, p. 333-359, 2002.

LOGUERCIO, R. Q. A dinâmica de analisar livros didáticos com professores de química. Química Nova, São Paulo, v. 24, n. 4, p. 557-562, 2001.

LOPES, A. R. C. Livros didáticos: obstáculos ao aprendizado ao aprendizado da ciência química I - obstáculos animistas e realistas. Química Nova, São Paulo, v. 15, n. 3, p. 254-261, 1992

MACHADO, N. Ensaios transversais: cidadania e educação. São Paulo: Escrituras, 1997.

MARTINS, R. A. Introdução: a história das ciências e seus usos na educação. In: SILVA, C. C. (Org.). Estudos de história e filosofia das ciências: subsídios para a aplicação no ensino. São Paulo: Livraria da Física, 2006. p. 17-30.

Ciência versus historiografia: os diferentes níveis discursivos nas obras sobre história da ciência. In: ALFONSO-GOLDFARB, A. M.; BELTRAN, M. H. R. (Org.).

Escrevendo a história da ciência: tendências, propostas e discussões historiográficas. São Paulo: EDUC; Livraria Editora da Física; Fapesp, 2004. p. 115-145.

MATTHEWS, M. R. Historia, filosofía y enseñanza de las ciencias: la aproximación actual. Enseñanza de las Ciencias, Barcelona, v. 12, n. 2, p. 255-277, 1994.

MORTIMER, E. F. A evolução dos livros didáticos de química destinados ao ensino secundário. Em Aberto, Brasília, v. 7. n. 40, p. 24-41, 1988.

MORTIMER, E. F.; MACHADO, A. H. Química. São Paulo: Scipione, 2005.

NÓBREGA, O. S.; SILVA, E. R.; SILVA, R. H. Química. São Paulo: Ática, 2005.

PAIXÃO, F.; CACHAPUZ, A. Mudanças na prática de ensino da química pela formação dos professores em história e filosofia das ciências. Química Nova na Escola, São Paulo, n. 18, p. 31-36, 2003.

PERUZZO, F. M.; CANTO, E. L. Química geral e inorgânica. 3. ed. São Paulo: Moderna, 2003. v. 1. 
Vidal, P. H. O.; Porto, P. A.

PICKSTONE, J. V. Past and present knowledges in the practice of the history of science. History of Science, Bucks, v. 33, n. 100 pt. 2, p. 203-224, 1995.

PORTO, P. A. História e filosofia da ciência no ensino de química: em busca dos objetivos educacionais da atualidade. In: SANTOS, W. L. P.; MALDANER, O. A. (Org.). Ensino de química em foco. Ijuí: Editora Unijuí, 2010. p. 159-180.

REID, D. V.; HODSON, D. Ciencia para todos en secundaria. Madrid: Narcea, 1993.

SANTOS, W. L. P.; MALDANER, O. A. Apresentação. In: SANTOS, W. L. P.;

MALDANER, O. A. (Org.). Ensino de química em foco. Ijuí: Editora Unijuí, 2010. p. 13-22.

SANTOS, W. L. P.; MOL, G. S. Química e sociedade. São Paulo: Nova Geração, 2005.

SOLBES, J.; TRAVER, M. Resultados obtenidos introduciendo historia de la ciencia en las clases de física y química: mejora de la imagen de la ciencia y desarrollo de actitudes positivas. Enseñanza de las Ciencias, Barcelona, v. 19, n. 1, p. 151-162, 2001.

VIDAL, P. H. O. A história da ciência nos livros didáticos de química do PNLEM 2007. 103f. Dissertação (Mestrado em Ensino de Ciências) - Programa Interunidades em Ensino de Ciências, Universidade de São Paulo, São Paulo, 2009.

Artigo recebido em 12/07/2011. Aceito em 03/02/2012. 